Word Count: 5090 (including references)

\title{
Multi-informant predictors of Social Inclusion for students with Autism Spectrum Disorders attending mainstream school
}

\author{
Alice P. Jones ${ }^{1,2} \&$ Norah Frederickson ${ }^{2}$
}

Running Head: Predictors of social inclusion for pupils with ASD

\footnotetext{
${ }^{1}$ Department of Psychology, Goldsmiths College, University of London

${ }^{2}$ Research Department of Clinical, Educational and Health Psychology, Division of

Psychology and Language Sciences, University College London
} 


\begin{abstract}
This study examined differential profiles of behavioural characteristics predictive of successful inclusion in mainstream education for children with autism spectrum disorders (ASD) and comparison students. Multiple regression analyses using behavioural ratings from parents, teachers and peers found some evidence for differential profiles predicting peer acceptance and rejection. High levels of peer-rated shyness significantly predicted social rejection in comparison students only. Parent-rated prosocial behaviour also differentially predicted social acceptance; high-levels of prosocial behaviour predicted acceptance in comparison students, but low-levels were predictive for students with ASD. These findings suggest that schools may seek to augment traditional social skills programmes with awareness raising about ASD among mainstream pupils to utilise peers' apparent willingness to discount characteristics such as 'shyness'.
\end{abstract}

Keywords: Autism Spectrum Disorders, Social Inclusion, Education Corrsponding author's email: a.jones@gold.ac.uk 
Autistic Spectrum Disorders (ASD) affect around 1\% of children in the UK (Baird et al., 2006), and many of these children are likely to have special educational needs (SEN) requiring additional and special provision. International educational policy advocates inclusion of students with SEN in mainstream contexts (UNESCO, 1994) and in the UK, schools are required to make adjustments to enable children with SEN to be included in school life (DfEE, 2001). The assessment of outcomes for children included in mainstream education is key in current policy initiatives in both the US and UK (US Department of Education, DfES, 2003; 2002).

However, a survey by the Office for Standards in Education (OFSTED, 2004) concluded that the outcomes of inclusion were poorly monitored, with few schools evaluating their SEN provision systematically enough to test effectiveness and value for money. In 2005, Mary Warnock controversially challenged the policy of inclusion, expressing particular concerns about students' social and emotional outcomes and highlighted children with ASD as being especially at risk of poor outcomes (Warnock, 2005).

Children with ASD are characterized by marked impairments in reciprocal social interaction, communication, and by repetitive and restricted interests and behaviours (DSM-IV-TR, APA, 2000; ICD-10, WHO, 1992). As such, one the greatest challenges for an individual with ASD is navigating the social world. School can be the source of both challenge and opportunity for developing social skills and peer relationships. There are over 32,500 students with ASD in primary and secondary mainstream education (Office of National Statistics, 2008). However, research into the outcomes for students with ASD in mainstream classes is relatively scarce (Barnard, Prior, \& Potter, 2000; 
Humphrey \& Lewis, 2008b) and has predominantly focused on the assessment of negative outcomes such as bullying, anxiety, social isolation and loneliness (Bauminger \& Kasari, 2000; Chamberlain, Kasari, \& Rotheram-Fuller, 2007). More recently attention has turned to factors that can enhance the educational environment for children with ASD. Humphrey and Lewis (2008a) have identified school-based factors implicated in successful inclusion, such as: differentiation of work, developing a predictable and ordered environment, placing the student with ASD in quiet, 'well-behaved' classes and providing access to a knowledgeable member of staff for advice on ASD-specific issues. Successful inclusion may also be pursued using peer-mediated intervention strategies which have been shown to have a positive outcome for students with ASD and their mainstream peers (Kamps, Barbetta, Leonard \& Delquadri, 1994; Dugan, Kamps, \& Leonard, Watkins, Rheinburger et al, 1995).

Students with ASD are not a homogenous group (Tager-Flusberg \& Joseph, 2003) and child-specific characteristics are also likely impact on successful inclusion. Behavioural characteristics associated with school social inclusion in typically developing students are well documented (Newcomb, Bukowski, \& Pattee, 1993). However, previous research suggests a differential profile of behaviour characteristics predicting social inclusion for students with Moderate Learning Difficulties (MLD) in mainstream than those for mainstream students (Frederickson \& Furnham, 2004; Nabuzoka \& Smith, 1983).

Frederickson and Furnham (1998) have speculated that these differences may be understood in terms of Social Exchange Theory (Thibaut \& Kelley, 1959). This theory explains motivation for affiliation with others in relation to the perceived costs and 
benefits of interacting with them, set against some minimum level of expectation. In MLD/Mainstream research, the mainstream students who experienced greatest social acceptance were those who represented the highest 'benefit' traits (e.g. co-operation) and lowest 'cost' traits (e.g. disruptive, help-seeking), while those mainstream students experiencing social rejection showed the reverse pattern. Frederickson and Furnham (2004) showed a difference between the behavioural profiles associated with social acceptance and rejection for MLD and mainstream students. They suggested that social rejection was experienced by only those students with MLD who failed even to deliver the minimum benefits expected in terms of 'benefit' traits; and higher than average level of 'costly' behaviours appeared to be discounted. Conversely, those students with MLD who were socially accepted were characterized by low levels of 'costly' behaviours but were not expected to offer high levels of 'benefits'.

One method of assessing social inclusion of students with SEN involves using peer sociometric measures (Frederickson \& Furnham, 2004, Ochoa \& Olivarez, 1995). This study uses the Social Inclusion Survey (SIS; Frederickson \& Graham, 1999), which was specifically designed to assess social outcomes of inclusion and has good psychometric properties (Frederickson \& Furnham, 1998a, Frederickson \& Furnham, 2001). In addition to these peer ratings of social inclusion, this study also obtained reports on behaviour from parents and teachers. Clinically the use of multi-informant ratings is recommended (Verhulst \& Van der Ende, 2008) and is likely to be of particular relevance in decision-making on inclusion.

In summary, the main aim of this study was to investigate the behavioural characteristics reported by three different informants: peers, parents and teachers that 
predict both social acceptance and social rejection in the classroom for students with ASD and for a group of mainstream students without SEN matched for IQ and age. It is hoped that identifying these behavioural characteristics will assist education professionals in identifying students with ASD who are particularly vulnerable to social rejection. A second aim is that existing social skills programmes may be adapted to promote behaviours that are shown to be associated with social acceptance and reduce behaviours associated with rejection in order to maximize inclusion in mainstream education. In line with Social Exchange Theory and results from MLD samples ( Frederickson \& Furnham, 2004; Nabuzoka \& Smith, 1983), we predicted that the two groups would show differential profiles of behavioural characteristics predictive of social acceptance and rejection. Social acceptance in students with ASD was expected to be predicted by lower levels of 'cost' characteristics but not high levels of 'benefit' characteristic. Social acceptance in mainstream students was expected to be predicted by both high level of 'benefit' characteristics and low levels of 'cost' characteristics. Social rejection in students with ASD was expected to be predicted by low levels of 'benefit' characteristics, but not high levels of 'cost' characteristics. Social rejection in mainstream students was expected to be predicted by both low levels of 'benefit' characteristics and high levels of 'cost' characteristics.

\section{Method}

Participants: Participants for this study were 86 students attending mainstream primary and secondary schools in the county of Buckinghamshire. Half of these, 43 students, had a diagnosis of Autism Spectrum Disorder notified to the Local Authority following the 
National Autism Plan for children procedures (NIASA, 2003) and had ASD identified as the primary need on their Statement of Educational Special Needs (DfES, 2001). Recommended practice in the UK requires that a diagnosis of ASD is made by a multiagency team following a staged assessment process. If it is suspected that the child has special educational needs, the team should notify the Local Education Authority so that it can be formally ascertained whether the needs are such that school actions can be identified to address them or whether they are severe and warrant the provision by the Local Authority of additional resources that are specified in a Statement of special educational needs. Hence the 43 children with ASD in the present study had been both identified by a multi-agency team as meeting the diagnostic criteria for ASD and showing severe impairment of functioning in the school context, requiring a Statement of special educational needs. The remaining 43 participants were typically developing students from the same schools identified by their class teacher as having equivalent academic abilities to the ASD students recruited in that class.

Of the 86 participants, 79 were male (39 with a diagnosis of ASD) and 7 participants were female ( 4 with a diagnosis of ASD). These participants are a subset from a larger sample recruited to look at the behavioural, cognitive and affective profiles of students with a diagnosis of ASD attending schools, including special schools, in Buckinghamshire. Inclusion in this study was dependent on social inclusion data being available. All students taking part in this study attended mainstream school and received special provision in respect of their special SEN either through a specialised ASD unit in the school (27 students) or through a classroom support assistant, advised by a visiting specialist teacher (16 students). 
Participants' age and IQ data are detailed in Table 1. The majority were from White English backgrounds $(\mathrm{n}=65,76 \%), 10 \%$ Indian or Pakistani, 5\% White European, $2 \%$ Caribbean and $6 \%$ mixed race. The proportion from non-white minority ethnic groups is somewhat above the national average for secondary schools $(17 \%$,$) and primary$ schools (21\%) (DfES, 2006). Eligibility for free school meals was collected as an index of socioeconomic status, and $6 \%(\mathrm{n}=5)$ of pupils found to be eligible, somewhat lower than the percentage for secondary schools $(9.6 \%)$ and primary schools $(14.5 \%)$, nationally (DfES, 2004; Hansard, 2007).

Measures: Wechsler Abbreviated Scale of Intelligence (Wechsler, 1999): To give an estimate of general cognitive ability, the short-form of the Wechsler Abbreviated Scales of Intelligence was used. Two sub-tests, Vocabulary and Matrix Reasoning, were administered. T-scores and Full-Scale IQ (FSIQ) scores are reported in Table 1.

\section{[Table 1 Here]}

The Social Inclusion Survey (SIS; Frederickson \& Graham, 1999): A sociometric assessment assessing how willing children are to associate with classmates at school. In this study children were asked to indicate how much they like to work with each classmate at school. The measure uses a forced-choice format in which children are presented with a list of classmates' names in the order they appear in the class register. Opposite each name are four response options: a question mark (to indicate any classmates they did not know well enough to decide how much they like to work with them); a smiling face ('would be happy to work with'); a neutral schematic face ('don't 
mind whether they work with or not'); and a sad face ('rather not work with'). For each participant an index of acceptance was calculated by dividing the number of smiling faces received by the total number of ratings in categories other than 'don't know'. An index of rejection was calculated similarly using the number of sad faces received. Testretest reliabilities for acceptance and rejection have been reported at .70 to .78 over a 5week period (Frederickson \& Furnham, 1998a).

Strengths and Difficulties Questionnaire (SDQ; Goodman, 1997): A widely used and well-validated measure of adjustment and psychopathology in children. This study used the 25-item Teacher and Parent rated versions which both have five subscales: Prosocial behaviour, Conduct Problems, Hyperactivity, Emotional Problems, and Peer Problems. Internal consistencies in this study were comparable to those reported by Goodman (2001) ranging between $\alpha=.64-.83$ for parents and $\alpha=.66-.86$ for teachers (Goodman, 2001: $\alpha=.57-.77$ for parents and $\alpha=.70-.88$ for teachers).

'Guess Who' Social Behaviour \& Bullying Measure (Frederickson \& Graham, 1999): An unlimited nomination peer assessment measure adapted from Coie and Dodge (1983) was used where children were asked to identify anyone in their class who fitted each of the following behavioural descriptors:

'Co-operates' - this person is really good to have as part of your group because they are agreeable and co-operate. They join in, share and give everyone a turn.

'Disrupts' - this person has a way of upsetting everything when he or she gets in a group. They don't share and try to get everyone to do things their way.

'Seeks help' - this person is always looking for help. They ask for help even before they've tried very hard. 
'Shy' - this person is shy with other children, they always seem to work or play by themselves. It is hard to get to know this person.

These four descriptors were analyzed to show the proportion of classroom peers nominating each child as fitting each of the descriptors. Frederickson and Graham (1999) reported acceptable reliability and validity for scores on the Guess Who measure.

Procedure: Approval for the study and consent procedures was obtained from the University College London Ethics committee. Permission for participation was sought from all parents of students with ASD in the county of Buckinghamshire being educated in mainstream schools. Three parents chose not to participate. Informed consent for participation was then sought from parents of students nominated to the comparison group. Where consent was refused for the teacher's first choice, parents of alternative students were contacted. Permission for completion of the whole-class measures was obtained using an opt-out consent method from parents/carers of all students in mainstream classes in which a student with ASD was being educated. No parent refused consent for their child's participation in completing the whole-class measures. No student declined to participate or subsequently withdrew.

\section{Results}

\section{Social Inclusion}

Table 1 shows descriptive statistics for ASD and comparison students on Social Acceptance and Social Rejection measures from the SIS (Frederickson \& Graham, 1999) 
along with peer, parent and teacher reports of behaviour. Compared to the comparison group, students with ASD are rated by their classmates significantly less often as being someone with whom they would be happy to work and significantly more often as being someone with whom they would rather not work.

\section{Behavioural Measures}

The peer-rated Guess Who measure (Frederickson \& Graham, 1999) indicated that students with ASD were significantly less likely to be described as being 'cooperative' and significantly more like to be described as 'help-seeking' and 'shy' compared with those in the matched comparison group. There was no significant difference between the groups on nominations as 'disruptive'.

Parent and teacher ratings on the SDQ yielded significant group differences on all subscales except for Conduct Problems. Students with ASD were rated by their parents as and teachers being significantly more hyperactive, having greater emotional and peer problems and being less prosocial than those in the comparison group.

Prediction of Social Inclusion by peer, parent and teacher ratings on behavioural measures.

To test the effects of the parent, teacher and peer-rated behavioural measures on social acceptance and rejection, six hierarchical regression analyses were conducted. First, regression analyses assessed the link between social acceptance and four peer-rated descriptors in the Guess-Who. These four factors and group status (ASD $=1$ and comparison $=0$ ) were entered as independent variables. In the second step, two-way 
interaction terms were added (peer-rated factors $\mathrm{x}$ group status). The same steps were repeated for using social rejection as the dependent variable. The same steps were then repeated for Parent and Teacher rated information using the same analytical steps as detailed above (the subscales of the Parent, and then Teacher, SDQ were entered as independent variables).

\section{[TABLE 2 HERE]}

\section{Peer-Rating of Behaviour}

Social Acceptance. The analysis entering peer-rated Guess Who scores to predict social acceptance revealed a significant main effect of peer-rated behavioural features $\left(F_{(5,74)}=25.34, p<.001\right.$; adjusted $\mathrm{R}$ square $\left.=.63\right)$. Two significant variables contributed to this model; co-operation and shy (Table 2). Higher scores on co-operation were associated with greater acceptance, while higher scores on shyness were associated with lower acceptance. The interaction terms entered on the next step made no further contribution to the model.

$\underline{\text { Social Rejection. }}$ There was a significant main effect of peer-rated behaviour on social rejection $\left(F_{(5,74)}=12.47, p<.001\right.$; adjusted $\mathrm{R}$ square $\left.=.46\right)$. The only significant variable contributing toward this model was co-operation, where a lower level of cooperation was associated with greater social rejection (Table 2).There was a significant interaction effect between the peer rating of shyness and group status $\left(F_{(1,73)}=11.78\right.$, $p=.03$; adjusted $\mathrm{R}$ square $=.49$ ). To interpret the nature of the interaction, we followed a procedure for interactions between categorical and continuous variables (Jaccard \& 
Turrisi, 2003). In the case of the comparison group, for every unit increase in the rating of shy, social rejection increased significantly, by .91 of a standard deviation. For the ASD group, there was no significant effect of 'shy' on social rejection, social rejection increased by only .36 of a standard deviation with every unit increase of 'shy' (Figure 1).

\section{[TABLE 3 HERE]}

\section{Parent-Rating of Behaviour}

$\underline{\text { Social Acceptance. The analysis entering parent-rated SDQ scores to predict }}$ social acceptance revealed a significant main effect of parent-rated behavioural features $\left(F_{(6,48)}=4.56, p=.001\right.$; adjusted $\mathrm{R}$ square $\left.=.28\right)$ The only factor that significantly predicted outcome for this model was the SDQ hyperactivity subscale (Table 3) where higher hyperactivity scores were associated with lower social acceptance. There was also a significant interaction effect between prosocial behaviour and group status $\left(F_{(1,47)}=4.86\right.$, $p=.04$; adjusted $\mathrm{R}$ square $=.33$ ). To interpret the nature of the interaction between prosocial behaviour and group status, we followed the procedure outlined above (Jaccard $\&$ Turrisi, 2003). For the comparison group, for every unit increase in the rating of prosocial behaviour, social acceptance increased by .28 of a standard deviation. For the ASD group, social acceptance decreased .30 of a standard deviation with every unit increase of prosocial behaviour (Figure 2).

Social Rejection. There was a significant main effect of parent-rated behaviour on social rejection $\left(F_{(6,48)}=3.10, p=.012\right.$; adjusted $\mathrm{R}$ square $\left.=.19\right)$. No individual factors 
significantly predicted outcome for this model. However, there was a trend for hyperactivity, where higher levels of parent-rated hyperactivity were associated with greater rejection $(\mathrm{p}=.07)$ (Table 3$)$. The interaction terms entered on the next step made no further contribution to the model.

\section{[TABLE 4 HERE]}

\section{Teacher-Rating of Behaviour}

Social Acceptance. The analysis entering teacher-rated SDQ scores to predict social acceptance revealed only group status as a significant predictor of social acceptance $\left(F_{(6,67)}=4.75, p<.001\right.$; adjusted R square $\left.=.24\right)($ Table 4). Diagnosis of ASD was associated with lower levels of social acceptance. The interaction terms entered on the next step did not make any further contribution to the model.

$\underline{\text { Social Rejection. Group status was the only significant predictor of social }}$ rejection $\left(F_{(6,67)}=3.73, p=.003\right.$; adjusted R square $\left.=.18\right)($ Table 4). A diagnosis of ASD was associated with greater social rejection. The interaction terms entered on the next step did not make any further contribution to the model.

\section{Discussion}

This study set out to investigate behavioural predictors of social acceptance and social rejection for students with ASD and sex, age and IQ-matched comparison students attending mainstream schools. Scores on these measures indicated close correspondence 
with findings from previous studies of the social inclusion of students with SEN in mainstream schools (Frederickson \& Furnham, 2004; Nabuzoka \& Smith, 1983). Sociometric ratings showed that students with ASD were significantly less well accepted by their peers and had significantly higher social rejection ratings than comparison students.

Examination of differences between the behavioural profiles of the two groups revealed a high degree of consistency across raters. Students with ASD were reported to exhibit significantly lower levels of beneficial, prosocial behaviours and higher levels of 'costly' social and emotional difficulties than students in the comparison group. However the groups did not differ on levels of conduct problems and disruptive behaviours, which were low for both groups. Hence, peers rated students with ASD as being significantly less co-operative, more help-seeking and more shy than mainstream comparison students. These findings closely correspond with those reported by Frederickson, Simmonds, Evans and Soulsby (2007) in a sample of students with SEN, predominately with an ASD diagnosis. In the present study both parents and teachers rated students with ASD significantly higher than comparison students on SDQ scales assessing emotional problems, peer problems and hyperactivity, but significantly lower than comparison students on the prosocial behaviour scale. These findings are consistent with patterns of co-morbidity with other psychiatric disorders reported in children with autism (Simonoff et al., 2008).

The ratings of behaviour, obtained from peers, parents and teachers, were entered into multiple regression analyses in order to investigate significant predictors of social acceptance and social rejection. Social acceptance and rejection in comparison students 
were each expected to be predicted by both 'benefit' and 'costly' behaviours. By contrast, acceptance in students with ASD was expected to be predicted by lower levels of 'cost' characteristics but not high levels of 'benefit' characteristic. The reverse behavioural pattern was expected to predict social rejection.

There were no between-group differences for the Guess Who peer assessment measures in predicting social acceptance. Social rejection was negatively associated with co-operation for both groups, while high levels of shyness were positively associated with social rejection only for comparison students. No significant relationship was found between peer-assessed shyness and social rejection in students with ASD. Students with ASD were more frequently nominated as shy than comparison students. Frederickson et al. (2007) likewise reported that students with ASD were significantly more frequently nominated as shy than either mainstream classmates or those with other types of SEN. It might be hypothesized that for students with ASD the descriptor 'shy' is applied to their characteristic relatively asocial behaviour, is seen as part of the problems they have, and so allowances are made accordingly.

One surprising aspect of the peer-assessment results is that there are no significant associations with disruptive behaviour. Previous studies have consistently reported significant associations between peer-assessed disruption on the Guess Who and sociometric status (Newcomb et al., 1993). However, in this sample, parent, teacher and peer-reported disruption is low. For students with ASD this is consistent with reports of high rates of emotional difficulties, social difficulties and hyperactivity, but not conduct problems (Simonoff et al., 2008). The low levels of disruption also apparent in the 
mainstream comparison group may reflect the recommended practice of placing students with ASD in quiet, well-behaved classes (Humphrey \& Lewis, 2008b).

While low levels of parent-rated hyperactivity significantly predicted social acceptance for both students with ASD and mainstream comparison students, there was a significant interaction between group and prosocial behaviour. For mainstream comparison students there was a trend for prosocial behaviour to be positively associated with social acceptance, but for students with ASD the trend was in the opposite direction. Those students with ASD who had higher levels of parent-rated prosocial behaviour tended to be less well accepted by peers as workmates. It may be that the more 'typical' the social behaviour of the ASD students, the fewer special concessions classmates considered warranted. Such effects have been reported previously, for example from an observational study of students with severe learning difficulties and mainstream classmates (Evans, Salisbury, Palombaro, Berryman, \& Hollowood, 1992). Alternatively, it may be that the very behaviour that parents of students with ASD perceive as prosocial is actually perceived as problematic by their peers. For example, students with ASD who try to be 'helpful if someone is hurt, upset or feeling ill' may have the opposite effect to that intended when the basic social skills needed for such interaction are lacking. While this may initially seem to be a discouraging finding, it is important to bear in mind that those children who are considered co-operative by their peers (regardless of diagnosis) are well accepted. Clearly, this is a finding that requires replication and further examination.

No teacher-ratings of behaviour predicted either social acceptance or rejection. This is a somewhat surprising finding given the important role ascribed to teacher attitude in 
creating an accepting ethos (Ward, Center, \& Bochner, 1994). It suggests that either that teachers' perceptions of children's behaviour, at least on the measure used in this study, are not significantly associated with social acceptance by classmates or that they are not communicated to them. It must be acknowledged that although the measure used in this study is a well-validated screening measure of children's strengths and difficulties, it may be less sensitive than other previously used measures in identifying social behaviours important in peer acceptance (Wright \& Torrey, 2001). Alternatively, there is evidence that teachers seek to avoid communicating their appraisal of the behavioural problems experienced by children with SEN and instead model acceptance (Janney, et al., 1995). One further limitation of this study to note is that the available sample size for this study may be a little low to detect all of the significant predictors of social inclusion. The use of multiple regression analyses to investigate the possible predictors of social acceptance and rejection from three different informant sources, and the resulting greater chance of type-one error should also be borne in mind. However, this study was designed as an investigation into predictors of social inclusion for students with ASD in mainstream schools and requires replication before firm conclusion can be drawn about the most important predictors for successful inclusion.

The findings of this study cast doubt on whether 'not making them different' is the best approach in promoting the social inclusion of students with ASD. It might be predicted that treating students with ASD as different and deserving of special consideration would be important in preventing characteristic asocial behaviour being perceived in a negative way. It must be acknowledged that such implications are only suggested by the current study of associations and will require evaluation in an 
intervention study. It would be of particular interest to examine social inclusion in schools with different inclusion policies, including those who have specialist ASD education for pupils.

A number of implications can be drawn on the basis of the present findings. Cooperation has emerged as an important factor in both social acceptance and rejection for all children. Intervention strategies for students with ASD often focus on social skills training (Bauminger, 2002) which has been widely advocated as an important means of promoting social acceptance and successful inclusion (Merrell \& Gimpel, 1998). We suggest that schools may feel confident about applying generic social skills programmes, which typically place much emphasis on the development of co-operative behaviours. However they may also seek to augment such programmes with awareness-raising about ASD among mainstream pupils to utilise peers' apparent willingness to discount characteristics such as 'shyness'. 


\section{REFERENCES}

Association, A. P. (2000). Diagnostic and Statistical Manual of Mental Disorders - 4th Edition, Text Revision. Washington, DC: : American Psychiatric Association.

Baird, G., Simonoff, E., Pickles, A., Chandler, S., Loucas, T., Meldrum, D., et al. (2006). Prevalence of disorders of the autism spectrum in a population cohort of children in South Thames - the special needs and autism project (SNAP). Lancet, 368, $210-215$.

Barnard, J., Prior, A., \& Potter, D. (2000). Autism and inclusion: Is it working? London: National Autistic Society.

Bauminger, N. (2002). The facilitation of social-emotional understanding and social interaction in high functioning children with autism: intervention outcomes. Journal of Autism and Developmental Disorders, 32, 283-298.

Bauminger, N., \& Kasari, C. (2000). Loneliness and friendship in high-functioning children with autism. Child Development, 71, 447-456.

Chamberlain, B., Kasari, C., \& Rotheram-Fuller, E. (2007). Involvement or isolation? The social networks of children with autism in regular classrooms. Journal of Autism and Developmental Disorders, 37, 230-242.

Coie, J. D., \& Dodge, K. A. (1983). Continuities and change in children's social status: A five-year longitudinal study. Merrill-Palmer Quarterly, 29, 261-282.

DfEE. (2001). Special Educational Needs and Disability Act. London: The Stationery Office Limited o. Document Number)

DfES. (2001). Special educational needs Code of Practice. London: DfES. 
DfES. (2003). Every Child Matters. London: The Stationery Office.

Department for Education and Skills (DfES) (2004). Trends in education and skills. National statistics. Overview and school inspections (OFSTED). Retrieved August 28, 2009, from www.dfes.gov.uk/trends/upload/xls/3_1t.xls

DfES. (2006). Ethnicity and Education. The Evidence on Minority Ethnic Pupils Aged 516. Nottingham: DfES Publications.

Dugan, E., Kamps, D., Leonard, B., Watkins, N., Rheinberger, A., \& Stackhaus, J. (1995). Effects of cooperative learning groups during social studies for students with autism and fourth grade peers. Journal of Applied Behavior Analysis, 28, $175-188$

Education, U. D. o. (2002). No Child Left Behind. Public Law: 107-110. Washington, DC: US Department of Education.

Evans, I. M., Salisbury, C. L., Palombaro, M. M., Berryman, J., \& Hollowood, T. M. (1992). Acceptance of elementary-aged children with severe disabilities in an inclusive school. Journal of the Association for Persons with Severe Handicaps, 17, 205-212.

Frederickson, N., \& Graham, B. (1999). Social Skills and Emotional Intelligence: Psychology in education portfolio. Windsor: NFER-Nelson.

Frederickson, N., Simmonds, E., Evans, L., \& Soulsby, C. (2007). Assessing the social and affective outcomes of inclusion British Journal of Special Education,, 34, 105-115. 
Frederickson, N. L., \& Furnham, A. F. (1998). Sociometric classification methods in school peer groups: A comparative investigation. Journal of Child Psychology and Psychiatry, 39, 921-934.

Frederickson, N. L., \& Furnham, A. F. (2001). The long-term stability of sociometric status classification: a longitudinal study of included pupils who have moderate learning difficulties and their mainstream peers. Journal of Child Psychology and Psychiatry, 42, 581-592.

Frederickson, N. L., \& Furnham, A. F. (2004). Peer-assessed behavioural characteristics and sociometric rejection: differences between pupils who have moderate learning difficulties and their mainstream peers. British Journal of Educational Psychology, 74, 391-410.

Goodman, R. (1997). The Strengths and Difficulties Questionnaire: A research note. Journal of Child Psychology and Psychiatry, 38, 581-586.

Goodman, R. (2001). Psychometric properties of the Strengths and Difficulties Questionnaire. Journal of the American Academy of Child \& Adolescent Psychiatry, 40, 1337-1345.

Hansard. (2007). Information on free school meals for maintained nursery, primary and secondary schools for January 2007: 3 Sep 2007: Column 1716W. http://www.publications.parliament.uk/pa/cm200607/cmhansrd/cm070903/text/70 903w0029.htm.

Humphrey, N., \& Lewis, S. (2008a). 'Make me normal': The views and experiences of pupils on the autistic spectrum in mainstream secondary schools. Autism, 12, 2346. 
Humphrey, N., \& Lewis, S. (2008b). What does "Inclusion" mean for pupils on the Autistic Spectrum in mainstream secondary schools? Journal of Research in Special Educational Needs.

Kamps, D. M., Barbetta, P. M., Leonard, B. R., \& Delquadri, J. (1994). Classwide peer tutoring: an integration strategy to improve reading skills and promote peer interactions among students with autism and general education peers. Journal of Applied Behavioral Analysis, 27, 49-61.

Jaccard, J., \& Turrisi, R. (2003). Interaction effects in multiple regression (2nd ed.). Thousand Oaks, CA: Sage Publications.

Merrell, K. M., \& Gimpel, G. A. (1998). Social skills of children and adolescents: Conceptualization, assessment, and treatment. Mahwah, NJ: Erlbaum.

Nabuzoka, D., \& Smith, P. K. (1983). Sociometric status and social behaviour of children with and without learning difficulties. Journal of Child Psychology and Psychiatry, 34, 1435-1448.

Newcomb, A. F., Bukowski, W. M., \& Pattee, L. (1993). Children's peer relations: A meta-analytic review of popular, rejected, neglected, controversial and average sociometric status. Psychological Bulletin, 113, 99-128.

NIASA, (2003). National Autism Plan for Children. London: National Autistic Society.

Ochoa, S. H., \& Olivarez, A. (1995). A meta-analysis of peer rating sociometric studies of pupils with learning disabilities. Journal of Special Education, 29, 1-19.

OFSTED. (2004). Special Educational Needs and Disability: towards inclusive schools. London: OFSTED. 
Simonoff, E., Pickles, A., Charman, T., Chandler, S., Loucas, T., \& Baird, G. (2008). Psychiatric disorders in children with autism spectrum disorders: Prevalence, comorbidity, and associated factors in a population-derived sample. Journal of the American Academy of Child \& Adolescent Psychiatry, 47, 921-929.

Statistics, O. o. N. (2008). Special Educational Needs in England. London: DfES.

Tager-Flusberg, H., \& Joseph, R. M. (2003). Identifying neurocognitive phenotypes in autism. Philosophical Transactions of the Royal Society B: Biological Sciences, $358,303-314$.

Thibaut, J. W., \& Kelley, H. H. (1959). The social Psychology of Groups. New York: Wiley.

UNESCO. (1994). The Salamanca statement and framework for action on special education. Paris: UNESCO.

Verhulst, F., \& Van der Ende, J. (2008). Rating scales. In M. Rutter, D. Bishop, D. Pine, S. Scott, J. Stevenson, E. Taylor \& A. Thapar (Eds.), Rutter's Child and Adolescent Psychiatry (pp. 70-86). Oxford: Blackwell.

Ward, J., Center, Y., \& Bochner, S. (1994). A question of attitudes: Integrating children with disabilities into regular classrooms? . British Journal of Special Education,, 21, 34 - 39 .

Warnock, M. (2005). Special Educational Needs: a New Look. London: Philosophy of Education Society of Great Britain.

Wechsler, D. (1999). Wechsler Abbreviated Scales of Intelligence. San Antonio, TX,: The Psychological Corporation. 
WHO. (1992). The ICD-10 classification of mental and behavioral disorders: Clinical descriptions and diagnostic guidelines. Geneva: WHO.

Wright, D., \& Torrey, K. (2001). A comparison of two peer-referenced assessment techniques with parent and teacher ratings of social skills and problem behaviors. Behavioural Disorders, 26, 173 - 182. 


\section{Tables and Figures}

Table 1: Participant characteristics and scores on measures of Behaviour, rated by parents, teachers and peers by group.

\begin{tabular}{|c|c|c|c|c|c|c|}
\hline & \multicolumn{2}{|c|}{ ASD } & \multicolumn{2}{|c|}{ Control } & \multirow[b]{2}{*}{$F$} & \multirow[b]{2}{*}{$p$-value } \\
\hline & mean & $\mathrm{SD}$ & mean & SD & & \\
\hline $\mathrm{n}$ & \multicolumn{2}{|c|}{43} & \multicolumn{2}{|c|}{43} & & \\
\hline Age & $11 \mathrm{y} 2 \mathrm{~m}$ & $(1 \mathrm{y} 4 \mathrm{~m})$ & $11 \mathrm{y} 4 \mathrm{~m}$ & $(2 \mathrm{y} 6 \mathrm{~m})$ & .19 & .66 \\
\hline Vocabulary t-score & 43.98 & $(13.65)$ & 50.53 & $(11.40)$ & 5.85 & .02 \\
\hline Matrix Reasoning t-score & 49.23 & $(9.66)$ & 47.23 & $(11.12)$ & .79 & .38 \\
\hline FSIQ & 95.26 & $(15.27)$ & 98.72 & $(14.53)$ & 1.16 & .28 \\
\hline \multicolumn{7}{|l|}{ Behavioural Measures } \\
\hline SIS (n) & \multicolumn{2}{|c|}{41} & \multicolumn{2}{|c|}{39} & & \\
\hline $\begin{array}{l}\text { SIS: Happy to work with } \\
\text { SIS: Rather not work }\end{array}$ & .25 & .17 & .42 & .19 & 18.49 & $<.001$ \\
\hline with & .36 & .18 & .20 & .17 & 16.71 & $<.001$ \\
\hline Guess-Who (n) & \multicolumn{2}{|c|}{41} & \multicolumn{2}{|c|}{42} & & \\
\hline Co-operative & .36 & .23 & .51 & .24 & 8.84 & .004 \\
\hline Disrupts & .17 & .18 & .21 & .18 & .97 & .33 \\
\hline Help-Seeking & .30 & .20 & .20 & .16 & 7.08 & .009 \\
\hline Shy & .28 & .19 & .06 & .08 & 46.45 & $<.001$ \\
\hline Parent SDQ (n) & \multicolumn{2}{|c|}{33} & \multicolumn{2}{|c|}{27} & & \\
\hline Conduct Problems & 2.36 & 2.29 & 1.37 & 1.62 & 3.60 & .06 \\
\hline Hyperactivity & 7.18 & 2.26 & 4.63 & 2.87 & 14.87 & $<.001$ \\
\hline Emotional Problems & 4.79 & 2.79 & 2.30 & 1.98 & 15.23 & $<.001$ \\
\hline Peer Problems & 4.42 & 1.85 & 2.37 & 1.88 & 17.96 & $<.001$ \\
\hline Prosocial Behaviour & 5.45 & 1.89 & 8.03 & 2.08 & 25.29 & $<.001$ \\
\hline Teacher SDQ (n) & \multicolumn{2}{|c|}{40} & \multicolumn{2}{|c|}{38} & & \\
\hline Conduct Problems & 1.35 & 1.75 & .90 & 1.23 & 1.71 & .20 \\
\hline Hyperactivity & 5.73 & 2.63 & 3.87 & 2.65 & 9.63 & .003 \\
\hline Emotional Problems & 3.07 & 2.41 & 1.63 & 2.12 & 7.78 & .007 \\
\hline Peer Problems & 3.30 & 2.38 & 1.18 & 1.77 & 19.61 & $<.001$ \\
\hline Prosocial Behaviour & 4.45 & 2.22 & 6.50 & 2.57 & 14.27 & $<.001$ \\
\hline
\end{tabular}


Table 2: Multiple regression analyses predicting social acceptance and social rejection by peer-ratings of behaviour (Guess Who).

\begin{tabular}{|c|c|c|c|c|c|}
\hline \multicolumn{6}{|c|}{ Social Acceptance } \\
\hline Step No & Predictor & beta & $t$ & $F$ change $(d f)$ & R squared change \\
\hline \multirow{6}{*}{1} & & & & $25.34(5,74)$ & 0.63 \\
\hline & Co-operates & .60 & $7.66^{\mathrm{a}}$ & & \\
\hline & Disrupts & -.10 & -1.07 & & \\
\hline & Help-Seeking & -.01 & -0.06 & & \\
\hline & Shy & -.25 & $-2.57^{\mathrm{b}}$ & & \\
\hline & Group Status & -.12 & -1.35 & & \\
\hline \multicolumn{6}{|c|}{ Social Rejection } \\
\hline Step No & Predictor & beta & $t$ & $F$ change $(d f)$ & $\mathrm{R}$ squared change \\
\hline \multirow{3}{*}{1} & & & & $12.47(5,74)$ & .46 \\
\hline & Co-operates & -.41 & $-4.31^{\mathrm{a}}$ & & \\
\hline & Disrupts & .18 & 1.62 & & \\
\hline \multirow{5}{*}{2} & Help-Seeking & 11 & .98 & & \\
\hline & Shy & .06 & .51 & & \\
\hline & Group Status & .26 & $2.31^{\mathrm{c}}$ & & \\
\hline & & & & $4.99(1,73)$ & .04 \\
\hline & $\begin{array}{l}\text { Shy x Group Status } \\
\text { Interaction }\end{array}$ & -.55 & $-2.23^{\mathrm{c}}$ & & \\
\hline
\end{tabular}


Table 3: Multiple regression analyses predicting social acceptance and social rejection

by parent-ratings of behaviour (SDQ).

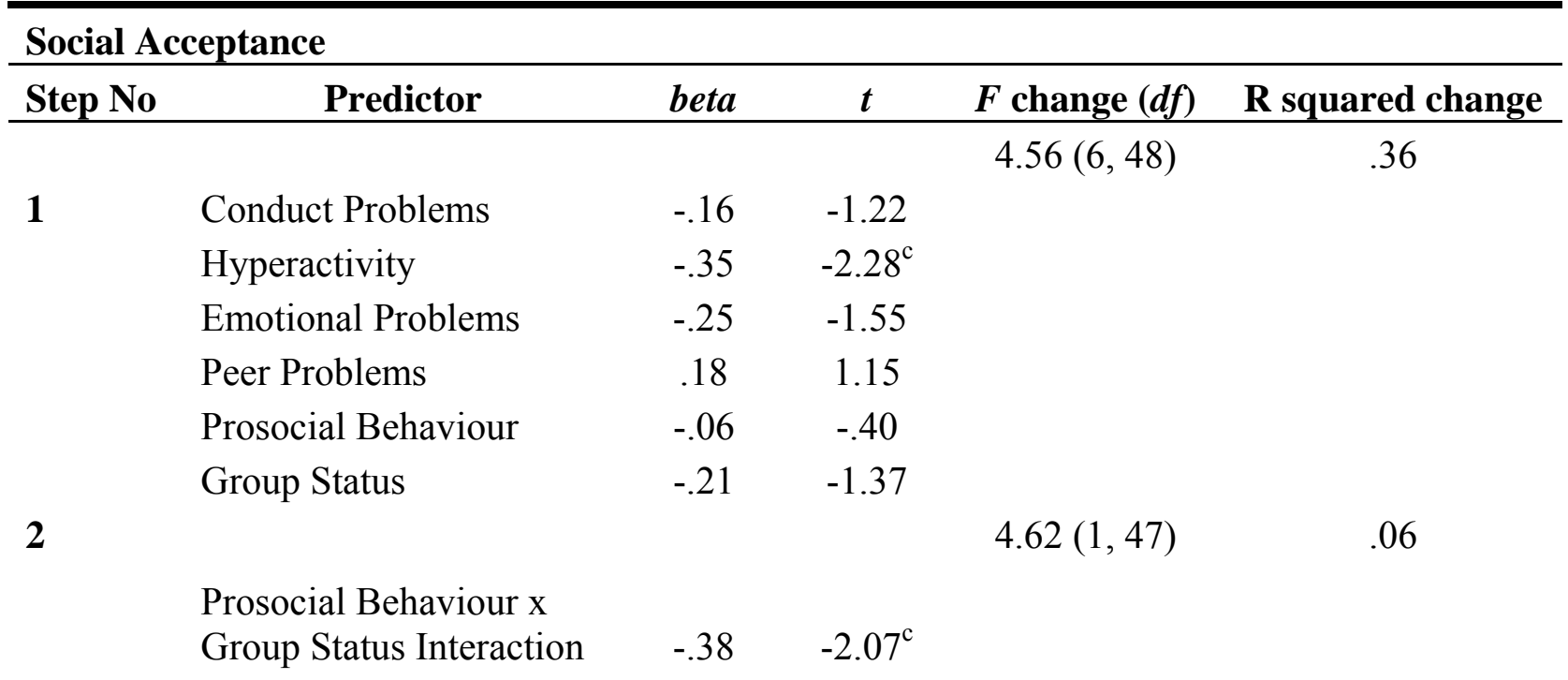

Social Rejection

\begin{tabular}{llcccc}
\hline Step No & \multicolumn{1}{c}{ Predictor } & beta & $\boldsymbol{t}$ & $\boldsymbol{F}$ change $(\boldsymbol{d} \boldsymbol{f})$ & R squared change \\
\hline & & & & $3.10(6,48)$ & .28 \\
& Conduct Problems & 0.11 & .77 & & \\
& Hyperactivity & .30 & 1.85 & & \\
Emotional Problems & .17 & 1.03 & & \\
& Peer Problems & -.01 & -.04 & & \\
& Prosocial Behaviour & 0.10 & 63 & & \\
& Group Status & 0.17 & 1.04 & & \\
\end{tabular}

$\mathrm{a}=\mathrm{p}<.001, \mathrm{~b}=\mathrm{p}<.01, \mathrm{c}=\mathrm{p}<.05$ 
Table 4: Multiple regression analyses predicting social acceptance and social rejection by teacher-ratings of behaviour (SDQ).

\begin{tabular}{|c|c|c|c|c|c|}
\hline \multicolumn{6}{|c|}{ Social Acceptance } \\
\hline Step No & Predictor & beta & $t$ & $F$ change $(d f)$ & R squared change \\
\hline & & & & $4.75(6,67)$ & .30 \\
\hline \multirow[t]{6}{*}{1} & Conduct Problems & -.04 & -.39 & & \\
\hline & Hyperactivity & -.16 & -1.25 & & \\
\hline & Emotional Problems & -.09 & -.79 & & \\
\hline & Peer Problems & -.16 & -1.20 & & \\
\hline & Prosocial Behaviour & -.13 & -0.97 & & \\
\hline & Group Status & -.36 & $-2.95^{b}$ & & \\
\hline \multicolumn{6}{|c|}{ Social Rejection } \\
\hline Step No & Predictor & beta & $t$ & $F$ change $(d f)$ & R squared change \\
\hline & & & & $3.73(6,71)$ & .25 \\
\hline \multirow[t]{6}{*}{1} & Conduct Problems & .05 & .41 & & \\
\hline & Hyperactivity & .10 & .72 & & \\
\hline & Emotional Problems & .01 & .11 & & \\
\hline & Peer Problems & .22 & 1.54 & & \\
\hline & Prosocial Behaviour & .21 & 1.58 & & \\
\hline & Group Status & .38 & $2.98^{\mathrm{b}}$ & & \\
\hline
\end{tabular}

$\mathrm{a}=\mathrm{p}<.001, \mathrm{~b}=\mathrm{p}<.01, \mathrm{c}=\mathrm{p}<.05$ 
Figure 1: Scatterplot depicting interaction between peer ratings of shyness and group status on social rejection.

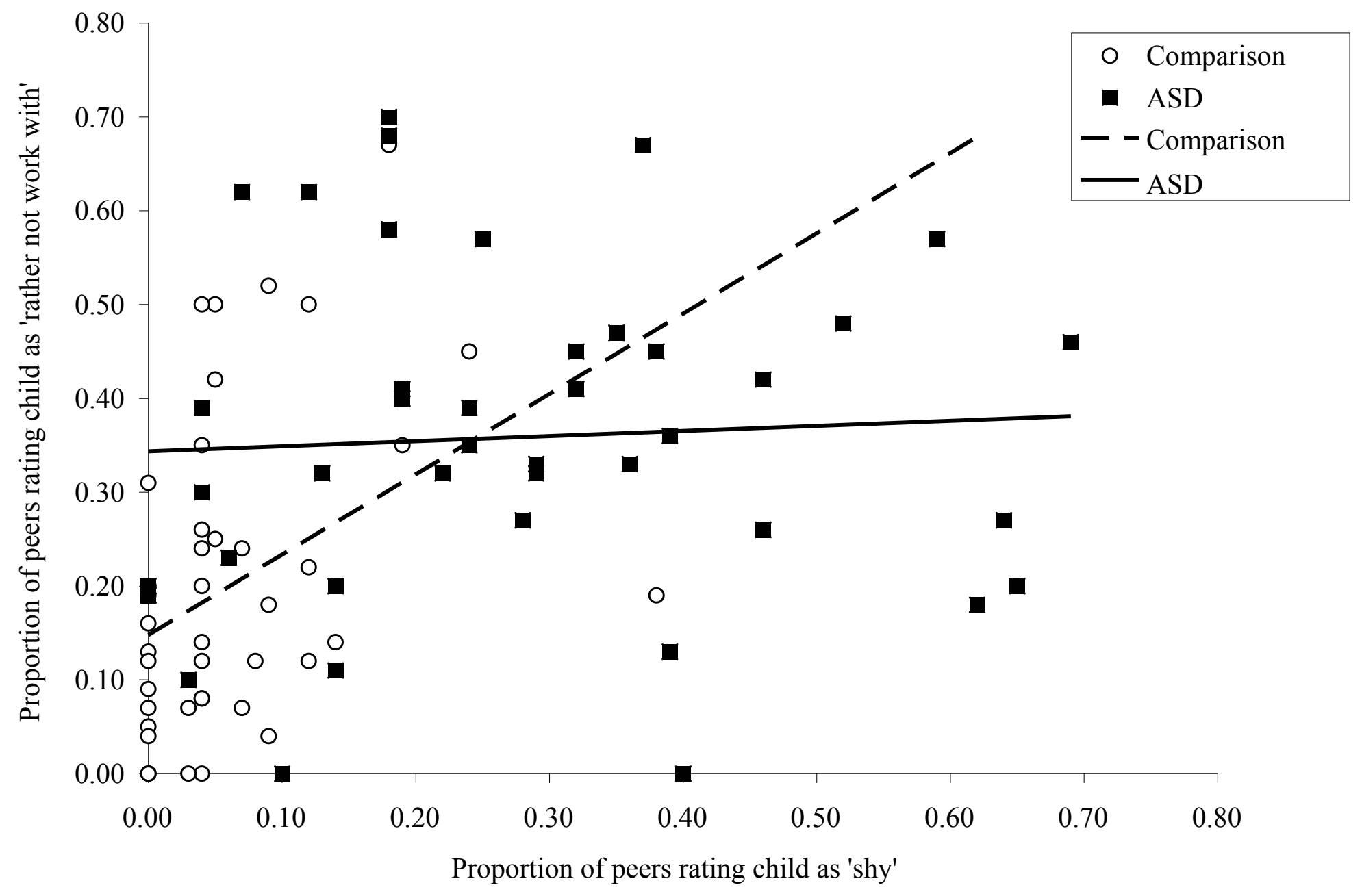


Figure 2: Scatterplot depicting interaction between parent ratings of prosocial behaviour and group status on social acceptance.

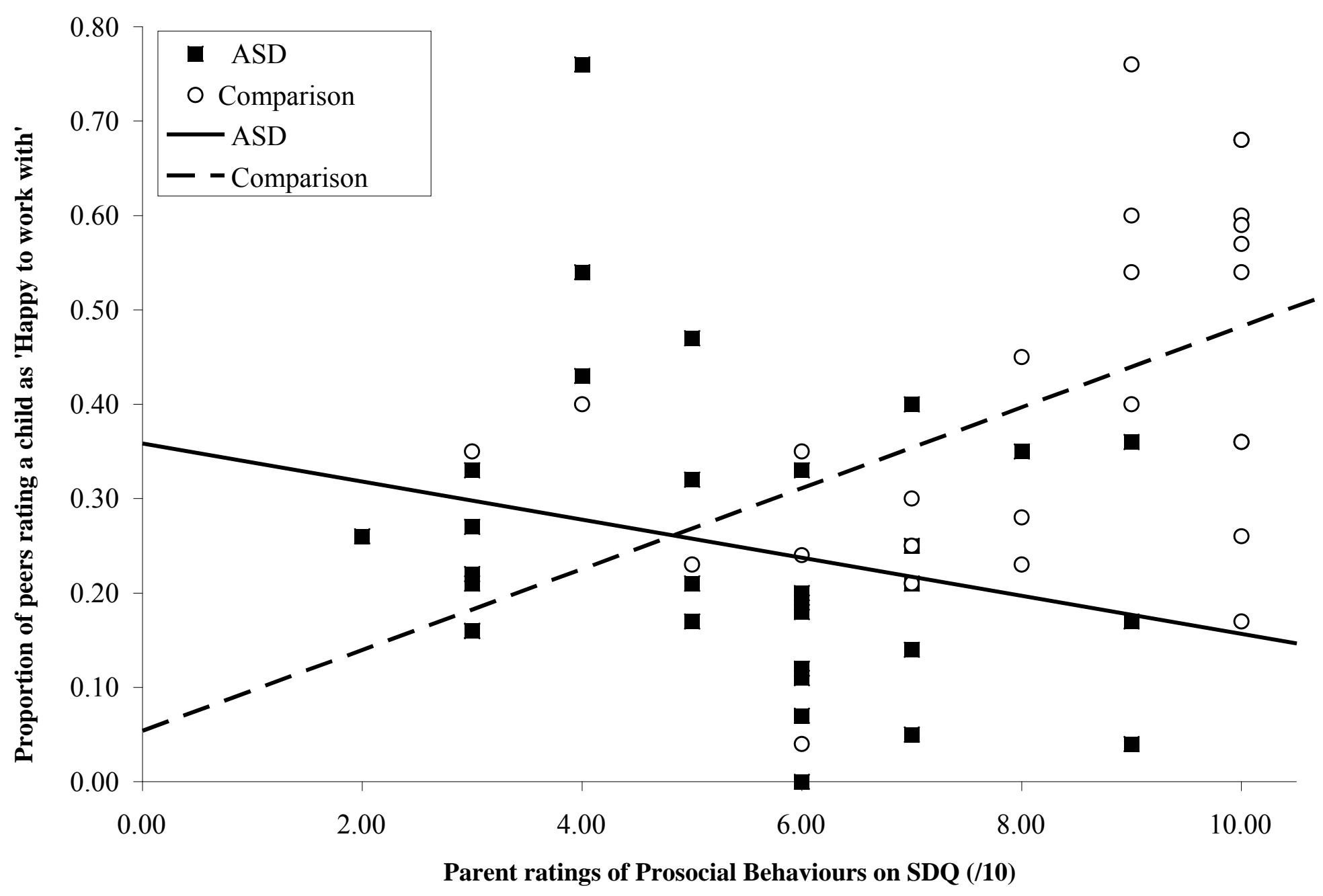




\section{Authors:}

Alice P. Jones: Department of Psychology, Goldsmiths College, University of London, Lewisham Way, London, SE14 6NW and Department of Clinical, Educational and Health Psychology, Division of Psychology and Language Sciences, University College London. UK

Norah Frederickson: Department of Clinical, Educational and Health Psychology, Division of Psychology and Language Sciences, University College London. UK

Acknowledgements: The authors would like to thank the parents, teachers and students who took part in this study. This work was supported by Buckinghamshire County Council. AJ is also supported by a Postdoctoral Fellowship from the ESRC (PTA-026-27-1981).

Correspondence to: Dr Alice Jones, Department of Psychology, Goldsmiths College, University of London, Lewisham Way, London, SE14 6NW

Tel: +44 (0)207 6795394 Email: a.jones@gold.ac.uk 